Detrás de la maleza sorprendido en su mudo aspaviento mágico, un pujido de luz enmarca el semillerío de los pájaros, piruetas y espiguetas sonoras pespunteando cables invisibles.

Pespunteando cables, invisibles hilos que cruzan con su lápiz el cielo, embadurnando y borrando la plancha gris, mascullando mendrugos y ruido que en un instante de estática enmarcan al amanecer.

Enmarcan al amanecer, y a este árbol quieto en su hueco, y a mis hijos en su respiración, y a la curruca en su griterío, y al ferrocarril en un solo haz de inmovilidad y estampida.

Pauline Drive, Chevy Chase, 8 de julio de 2010.

\title{
NIÑOS Y TORTUGAS
}

Mis hijos aprenden a nadar, como dos tortugas recién salidas de la blandura arenada del huevo, al pozo de amor y cobijo donde los esperamos hasta hoy. Agitan los brazos y pies, las aletas grumosas, se desesperan y desconocen, avanzan en la vida por minutos, hasta que quedan ya, ágiles y diminutas monedas de cobre y viento que corren por la playa, ruedan, 
se internan en la inmensidad de la ola.

Con la ayuda del mar, o de los suyos, se han librado de perros y pelícanos, patos buzos y otros humanos

y empiezan a ir solas en el agua, sumergen la cabeza, mueven un brazo y el otro, en ese medio antiguo, acosador y hostil y cálido. Con aprendizaje de signos o de millones de años viajan hacia la madre del mar, peligro y familia. En el espacio de lo inopinado se desenvuelven, con trabajo agarran el mar.

Nosotros somos la raíz y el costado.

San Agustinillo, 2006, probablemente.

$*$

\section{DienteCillos}

Como un maravedí el primer diente de mi hijo, una joya frutal y peligrosa, un dulce a la vista.

Ahora que se le ha caído

parece una pieza de marquetería,

un marfil en cajita de luces,

una joya de tiempo en vilo, brillando, duro.

Entre uno y otro cinco años

de recolección y subsistencia, nómadas en el jardín de la vida, peregrinos en el trazo de calles, casas, suerte.

Reconocemos los meses como altiplanos, valles o playas.

Cada detalle que acumulamos es historia común.

Haz de familia, destello.

Es lo que somos juntos.

Igual a ellos.

Fósiles al viento, piezas de humanidad,

dientecillos de vida. 